\title{
PENERAPAN TEKNOLOGI DALAM MEMAKSIMALKAN PENJUALAN TEH DI INDONESIA
}

\section{Application of Technology in Maximizing Sales of Tea on Indonesia}

\author{
Desi Putriani ${ }^{1 *}$, Dessyana Kardha ${ }^{1}$ \\ Program Studi Sistem Informasi STMIK AUB Surakarta \\ *Corresponden author : 2157100806@stmik-aub.ac.id
}

\begin{abstract}
Tea is one of the leading agricultural commodities in Indonesia as the seventh largest tea producer in the world. Today's drinks are still consumed by many people as a refreshing drink or medicine. An infusion made by brewing leaves, shoots, or leaf stems dried from the Camellia sinensis plant with hot water. The purpose of this study is to build a sales application that is able to maximize tea sales so as to preserve tea production in the agricultural sector in Indonesia. In building the system the method of approach used is the waterfall method. Data collection methods by interview, observation and library methods. Using PIECES analysis and flowchart design, data Flow Diagrams and Entity Relationship Diagrams using java script, html, and php technology. The results of this research are making a tea-selling application on mobile-based yellow gambyong tea that can make it easier for people to make product purchases in the internet era and make it easier for tea businesses to manage and develop their businesses.
\end{abstract}

Keyword : Tea, Mobile, Digital, Selling.

\section{ABSTRAK}

Teh adalah salah satu komoditi unggul pertanian di Indonesia sebagai produsen teh terbesar ketujuh di dunia. Minuman yang di jaman ini masih dikonsumsi oleh banyak orang sebagai minuman penyegar maupun obat. Sebuah infusi yang dibuat dengan cara menyeduh daun, pucuk daun, atau tangkai daun yang dikeringkan dari tanaman Camellia sinensis dengan air panas. Tujuan penelitian ini adalah membangun sebuah aplikasi penjualan yang mampu memaksimalkan penjualan teh sehingga dapat melestarikan produksi teh di sektor pertanian di Indonesia. Dalam membangun sistem tersebut metode pendekatan yang digunakan adalah metode waterfall. Metode pengumpulan data dengan metode wawancara, metode observasi dan metode pustaka. Menggunakan analisa PIECES dan perancangan flowchart, data Flow Diagram serta Entity Relationship Diagram menggunakan teknologi java script, html, dan php. hasil dari penelitian ini adalah membuat suatu aplikasi penjualan teh pada teh gambyong kemuning berbasis mobile yang dapat mempermudah masyarakat untuk melakukan pembelian produk di era internet dan mempermudah pelaku usaha teh mengelola dan mengembangkan usahanya.

Kata kunci : Teh, Mobile, Digital, Penjualan.

\section{PENDAHULUAN}

Posisi Indonesia saat ini adalah produsen teh terbesar ketujuh di dunia. Meskipun ada penurunan luas lahan, jumlah produksi teh tetap stabil (Pratiwi, Ali, Setiawan, Budiyanto, \& Sucahyo, 2017). Hal ini mengindikasikan bahwa perkebunan-perkebunan teh yang tersisa lebih produktif. Teh menjadi primadona minuman khas yang cocok disegala musim dan banyak digemari segala usia. Selain itu teh sering dicari untuk kesehatan tubuh sebagai antioksidan, mencegah penyakit jantung mengurangi kolesterol dalam darah, memperbaiki sel yang rusak, menghaluskan kulit, melangsingkan tubuh, mencegah kanker, serta melancarkan sirkulasi darah.

Teh Gambyong Kemuning merupakan salah satu usaha potensi lingkungan yang memanfaatkan hasil 
perkebunan yaitu daun teh yang diolah menjadi teh seduh dalam kemasan. Terletak di Dusun Badan RT.04 RW.05 kemuning, Ngargoyoso, Karanganyar, mereka mengolah sendiri hasil petikan daun teh yang sudah di panen. Beberapa jenis teh yang di olah oleh Teh Gambyong yaitu Teh Hitam, Teh Hijau, Teh Putih, Teh Kapulaga, Teh Jahe, Teh Secang, Green Macha, dan Teh Curah Hitam Biasa. Hasil produksinya dikirim ke berbagai negara seperti Korea, Thailand, Croatia, Slovakia, USA, Malaysia, Bulgaria, dan Eropa.

Beberapa kendala yang dialami adalah kegiatan penjualan teh yang berjalan masih manual yaitu pelanggan datang langsung ke toko, memilih produk teh yang diminati, menanyakan harga ke pegawai, apabila sudah dipilih bisa langsung dibayar atau pembelian melalui Telefon atau SMS biasanya digunakan untuk pelanggan tetap, yang kemudian diantar atau dikirim sesuai ke pelanggan dan baru dibayar saat barang sudah sampai.

Sementara itu di jaman digital sekarang ini ,idealnya transaksi apapun bisa kita lakukan dalam genggaman menggunakan teknologi smartphone. Pelanggan sering menggunakan smartphone untuk mencari berbagai jenis produk salah satunya minuman teh yang sesuai kebutuhan. Menggunakan smartphone di era digital secara maksimal bisa menghemat waktu, menambah pelanggan dan memaksimalkan kinerja pegawai.

Berdasarkan permasalahan di atas maka peneliti memandang perlu untuk membuat sebuah aplikasi Penjualan Teh untuk memaksimalkan penjualan potensi produk dan melestarikan hasil pertanian teh di Indonesia berbasis mobile dengan menggunakan android. Sebelum membangun aplikasi dilakukan Analisa Lingkungan Sistem dengan menggunakan Analisa PIECES. Sehingga sistem yang dibangun benar-benar dapat bermanfaat bagi kelestarian produk teh di Indonesia.

\section{METODE PENELITIAN}

Jenis penelitian yang digunakan dalam penelitian ini adalah metode penelitian kuantitatif. Dimana penelitian kuantitatif adalah penelitian yang menggunakan pendekatan deduktifinduktif, yaitu berangkat dari suatu kerangka teori, gagasan para ahli, maupun pemahaman peneliti berdasarkan pengalamannya, kemudian dikembangkan menjadi pokok-pokok permasalahan beserta pemecahannya untuk memperoleh pembenaran (verifikasi) atau penilaian dalam bentuk dukungan data empiris di lapangan. Metode penelitian meliputi data dan teknik pengumpulan data, model penelitian dan metode analisis data. Analisa sistem dilakukan dalam membangun sebuah aplikasi dengan tujuan untuk memahami permasalahan yang ada pada sistem, menganalisa sistem yang lama dapat mengetahui ruang lingkup yang ada. Analisa sistem akan membahas mengenai analisa masalah, analisa kelemahan sistem, analisa kebutuhan sistem.

\section{Kajian Pustaka dan Pengembangan Hipotesis}

\section{Definisi Aplikasi}

Menurut Sutabri (2012), Aplikasi adalah alat terapan yang difungsikan secara khusus dan terpadu sesuai kemampuan yang dimilikinya. Asropudin (2013) menjelaskan bahwa Aplikasi adalah software yang dibuat oleh suatu perusahaan komputer untuk mengerjakan tugas-tugas tertentu.

\section{Definisi Teh}

Menurut Ajisaka (2012) teh merupakan suatu tanaman yang memiliki khasiat sebagai obat herbal. Tanaman teh memiliki ciri-ciri batang tegak, berkayu, bercabang-cabang, ujung ranting dan daun mudanya berambut halus. Tanaman teh juga memiliki daun tunggal, bertangkai pendek, letaknya berseling, helai daunya kaku, panjangnya 6-18 cm, lebarnya 2-6 $\mathrm{cm}$, warnanya hijau, dan permukaanya mengkilap. Teh yang baik dihasilkan dari 
bagian pucuk ditambah 2-3 helai daun mud, karena pada daun muda tersebut kaya akan senyawa polifenol, kafein serta asam amino. Senyawa - senyawa inilah yang akan mempengaruhi kualitas warna, aroma, dan rasa dari teh.

Kandungan senyawa kimia dalam daun teh terdiri dari tiga kelompok besar yang masing - masing mempunyai manfaat bagi kesehatan, yakni polifenol, kafein dan essentional. Selain itu di dalam teh juga terdpat beberapa vitamin seperti vitamin $\mathrm{A}$, vitamin $\mathrm{C}$, dan vitamin $\mathrm{E}$. Zatzat yag terdapat di dalam teh sangat mudah teroksidasi. Bila daun teh terkena sinar matahari, maka proses oksidasi pun terjadi . Adapun jenis teh yang umumnya dikenal dalam masyarakat adalah teh hijau, teh olong, teh hitam, dan teh putih.

\section{Definisi Android}

Menurut Supardi (2017) Android merupakan sebuah sistem operasi perangkat mobile berbasis linux yang mencakup sistem operasi, middleware, dan aplikasi. Banyak Smarphone dan Table yang menggunakan sistem operasi dengan versi yang berbeda. Semakin versi tinggi fiturnya, semakin canggih smartphone atau table tersebut. Telepon pertama yang memakai sistem operasi Android adalah HTC Dream yang diliris pada tanggal 22 Oktober 2008.

\section{Definisi Analisa PIECES}

Untuk mengurangi resiko kegagalan, maka harus dilakukan analisis terhadap ekonomi, pengendalian, efisiensi dan pelayanan atau juga sering disebut dengan analisis pieces. Adapaun pengertian dari analisis pieces sebagai berikut Al Fatta (2007):

\section{a. Analisis Kinerja Sistem (Performance)}

Kinerja adalah suatu kemampuan sistem dalam menyelesaikan tugas dengan cepat sehingga sasaran dapat segera tercapai. Kinerja diukur dengan jumlah produksi (throughput) dan waktu yang digunakan untuk menyelesaikan perpindahan pekerjaan (responsetime).

b. Analisis Informasi (Information)

Informasi merupakan hal penting karena dengan informasi tersebut pihak manajemen (marketing) dan user dapat melakukan langkah selanjutnya.

c. Analisis Ekonomi (Economy)

Pemanfaatan biaya yang digunakan dari pemanfaatan informasi.Peningkatan terhadap kebutuhan ekonomis mempengaruhi pengendalian biaya dan peningkatan manfaat.

d. Analisis Pengendalian (Control)

Analisis ini digunakan untuk membandingkan sistem yang dianalisa berdasarkan pada segi ketepatan waktu, kemudahan akses dan ketelitian data yang diproses.

e. Analisis Efisiensi (Efficiency)

Efisiensi berhubungan dengan bagaimana sumber tersebut dapat digunakan secara optimal. Operasi pada suatu perusahaan dikatakan efisien atau tidak biasanya didasarkan pada tugas dan tanggung jawab dalam menyelesaikan kegiatan.

f. Analisis Pelayanan (Service)

Peningkatan pelayanan memperlihatkan kategori yang beragam. Proyek yang dipilih merupakan peningkatan pelayanan yang lebih baik bagi manajemen (marketing), user dan bagian lain yang merupakan simbol kualitas dari suatu sistem informasi.

\section{HASIL DAN PEMBAHASAN}

\section{Analisa Kelemahan Sistem}

Untuk mengetahui kelemahan sistem maka penulis menggunakan metode analisa kelemahan sistem yaitu metode PIECES yang terdiri dari enam 
aspek, yaitu analisa kinerja (performance), informasi (Information), ekonomi (Economic), pengendalian (Control), efisiensi (Effeciency) dan pelayanan (Services). Berdasarkan penelitian yang dilakukan penulis, didapatkan bahwa :

\section{Analisa Kinerja (Performance)}

Sistem yang sedang berjalan di toko Teh Gambyong Kemuning masih seperti sistem jual beli pada umumnya, dimana belum adanya sistem yang menampung transaksi penjualan secara online, belum ada sistem yang menyajikan data barang secara akurat kepada pembeli secara langsung. Untuk laporan penjualan juga masih manual menggunakan form kertas.

2. Analisa Informasi (Information)

Untuk mendapatkan informasi mengenai ketersediaan produk atau mengenai manfaat produk terkadang pembeli masih mengalami kesulitan karena harus selalu bertanya kepada penjual karena informasi yang disajikan tidak lengkap.

3. Analisa Ekonomi (Economic)

Karena transaksi penjualan dilakukan di toko dengan cakupan yang tidak luas, maka pendapatan dari toko Teh Gambyong Kemuning ini kurang begitu bagus.

\section{Analisa Kontrol (Control)}

Sering terjadinya ketidakcocokan stok produk yang tercatat dengan stok produk yang tersedia menyebabkan ketidakpuasan pembeli pada toko Teh Gambyong Kemuning.

5. Analisa Efisiensi (Efficiency)

Untuk pencatatan pemesanan barang masih menggunakan catatan manual dan transaksi penjualan belum menyediakan transaksi secara online.

6. Analisa Pelayanan (Service)

Pelayanan yang diberikan sistem saat ini kurang akurat dan cepat dalam pemberian informasi yang dibutuhkan oleh pembeli.

\section{Analisa Sistem Yang Akan Dibangun}

Aplikasi ini memberikan fasilitas transaksi secara online sehingga pembeli tidak harus datang ke toko untuk membeli produk. Alur kerja aplikasi ini dapat dilihat pada gambar gambar berikut:
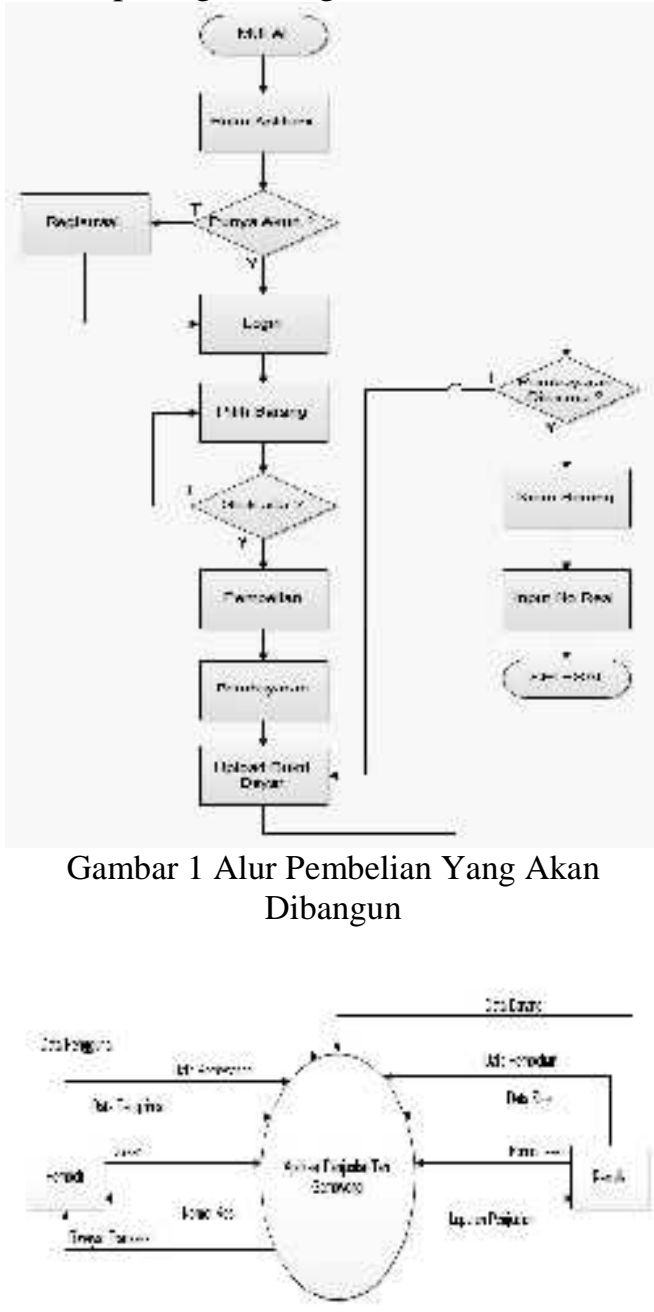

Gambar 2 Diagram konteks Aplikasi Penjualan Teh Gambyong Kemuning 


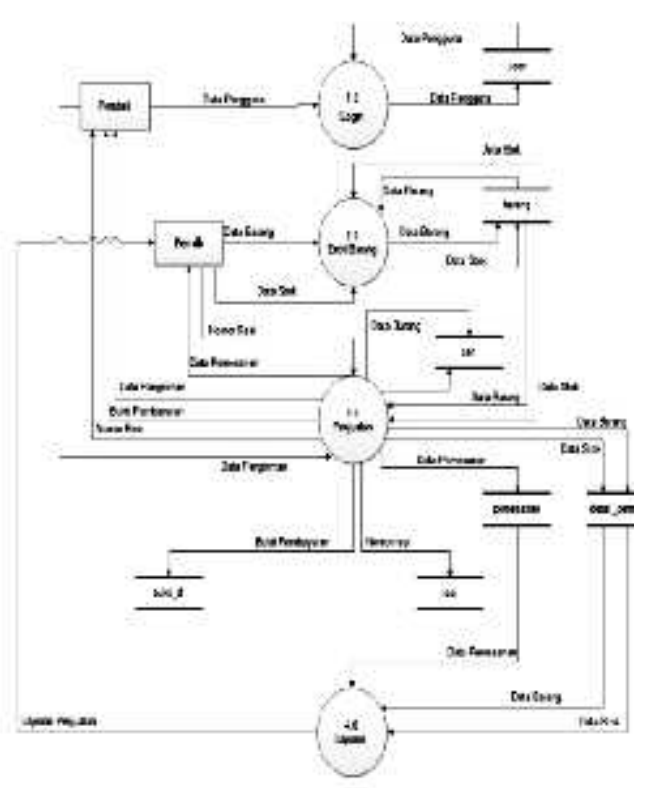

Gambar 3. Data Flow Diagram Level 1 Proses Master Data

Pada Gambar 4.3 DFD Level 1 menjelaskan 4 proses yaitu proses login, entri barang, proses penjualan, dan proses laporan. Pada proses login, digunakan untuk pembeli atau pengguna yang sebelumnya sudah mempunyai username dan password, akun tersembut sudah tersimpan di tabel user.

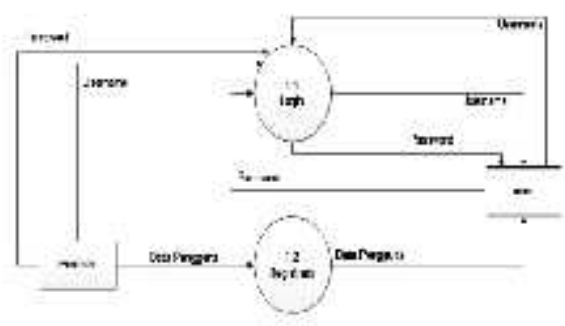

Gambar 4 Data Flow Diagram Level 1 Proses Login

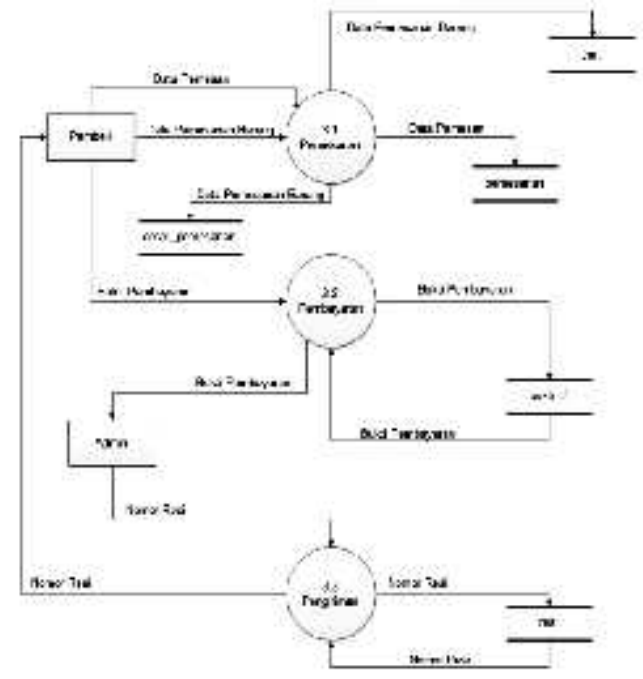

Gambar 5 Data Flow Diagram Level 1 Proses Penjualan

\section{Relasi Antar Tabel}

Relasi antar tabel merupakan penghubung antar tabel satu dengan tabel lainya yang mana tabel tersebut memiliki data yang berhubungan di dunia nyata untuk mengatur operasi satu database.

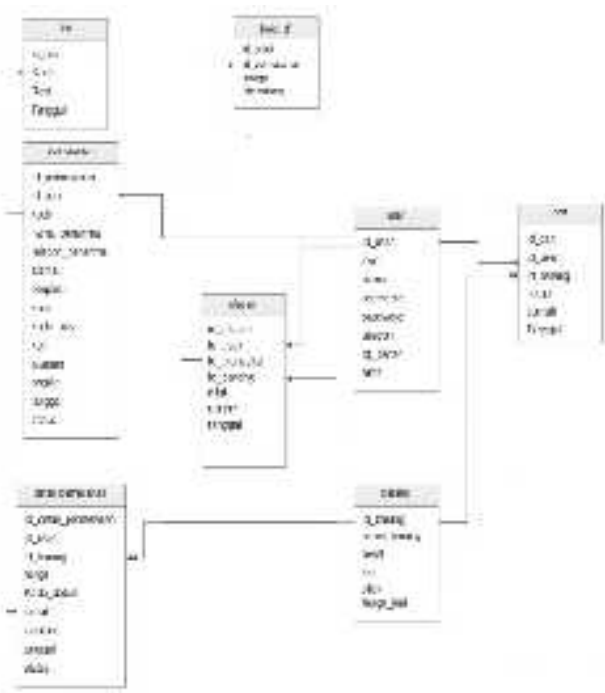

Gambar 6. Relational Diagram

\section{Implementasi}

\section{Uji Coba Sistem}

Sistem harus bebas dari kesalahan agar dapat dilanjutkan pada proses 
selanjutnya yaitu implementasi sistem dengan menggunakan blackbox testing sebagai metode pengujian sistem.

Tabel 1. Pengujian Aplikasi

\begin{tabular}{|c|c|c|c|c|}
\hline No & $\begin{array}{c}\text { Skenario } \\
\text { Pengujian }\end{array}$ & $\begin{array}{l}\text { Hasil yang } \\
\text { diharapkan }\end{array}$ & $\begin{array}{c}\text { Hasil } \\
\text { pengujian }\end{array}$ & $\begin{array}{c}\text { Kesim } \\
\text { pulan }\end{array}$ \\
\hline 1 & $\begin{array}{l}\text { Admin } \\
\text { memasuk } \\
\text { kan } \\
\text { username, } \\
\text { password } \\
\text { yang } \\
\text { salah }\end{array}$ & $\begin{array}{l}\text { Muncul } \\
\text { notifikasi } \\
\text { username } \\
\text { atau } \\
\text { password } \\
\text { salah. }\end{array}$ & $\begin{array}{c}\text { Sesuai } \\
\text { harapan }\end{array}$ & Valid \\
\hline 2 & $\begin{array}{l}\text { Admin } \\
\text { memilih } \\
\text { menu }\end{array}$ & $\begin{array}{l}\text { Sistem } \\
\text { menampil } \\
\text { kan } \\
\text { pilihan } \\
\text { data } \\
\text { barang } \\
\text { dan data } \\
\text { pengguna }\end{array}$ & $\begin{array}{c}\text { Sesuai } \\
\text { harapan }\end{array}$ & Valid \\
\hline 3 & $\begin{array}{l}\text { Admin } \\
\text { memasuk } \\
\text { an nama } \\
\text { barang, } \\
\text { berat, } \\
\text { keteranga } \\
\text { n dan foto } \\
\text { produk } \\
\text { dan klik } \\
\text { simpan } \\
\text { pada data } \\
\text { barang }\end{array}$ & $\begin{array}{l}\text { Sistem } \\
\text { berhasil } \\
\text { menambah } \\
\text { data } \\
\text { barang } \\
\text { dan } \\
\text { disimpan } \\
\text { oleh } \\
\text { admin }\end{array}$ & $\begin{array}{c}\text { Sesuai } \\
\text { harapan }\end{array}$ & Valid \\
\hline 4 & $\begin{array}{l}\text { Admin } \\
\text { memilih } \\
\text { button } \\
\text { edit data } \\
\text { barang }\end{array}$ & $\begin{array}{l}\text { Sistem } \\
\text { berhasil } \\
\text { mengubah } \\
\text { data barang } \\
\text { yang diedit } \\
\text { oleh admin }\end{array}$ & $\begin{array}{c}\text { Sesuai } \\
\text { harapan }\end{array}$ & Valid \\
\hline 5 & $\begin{array}{l}\text { Admin } \\
\text { memasuk } \\
\text { an nama, } \\
\text { user name } \\
\text { dan } \\
\text { password } \\
\text { dan klik } \\
\text { simpan } \\
\text { pada data } \\
\text { pengguna }\end{array}$ & $\begin{array}{l}\text { Sistem } \\
\text { berhasil } \\
\text { menambah } \\
\text { data } \\
\text { pengguna } \\
\text { dan } \\
\text { disimpan } \\
\text { oleh } \\
\text { admin }\end{array}$ & $\begin{array}{c}\text { Sesuai } \\
\text { harapan }\end{array}$ & Valid \\
\hline 6 & $\begin{array}{l}\text { Admin } \\
\text { memilih } \\
\text { menu data } \\
\text { laporan }\end{array}$ & $\begin{array}{l}\text { Sistem } \\
\text { menampilk } \\
\text { an pilihan } \\
\text { data laporan } \\
\text { pada } \\
\text { sistem }\end{array}$ & $\begin{array}{l}\text { Sesuai } \\
\text { harapan }\end{array}$ & Valid \\
\hline
\end{tabular}

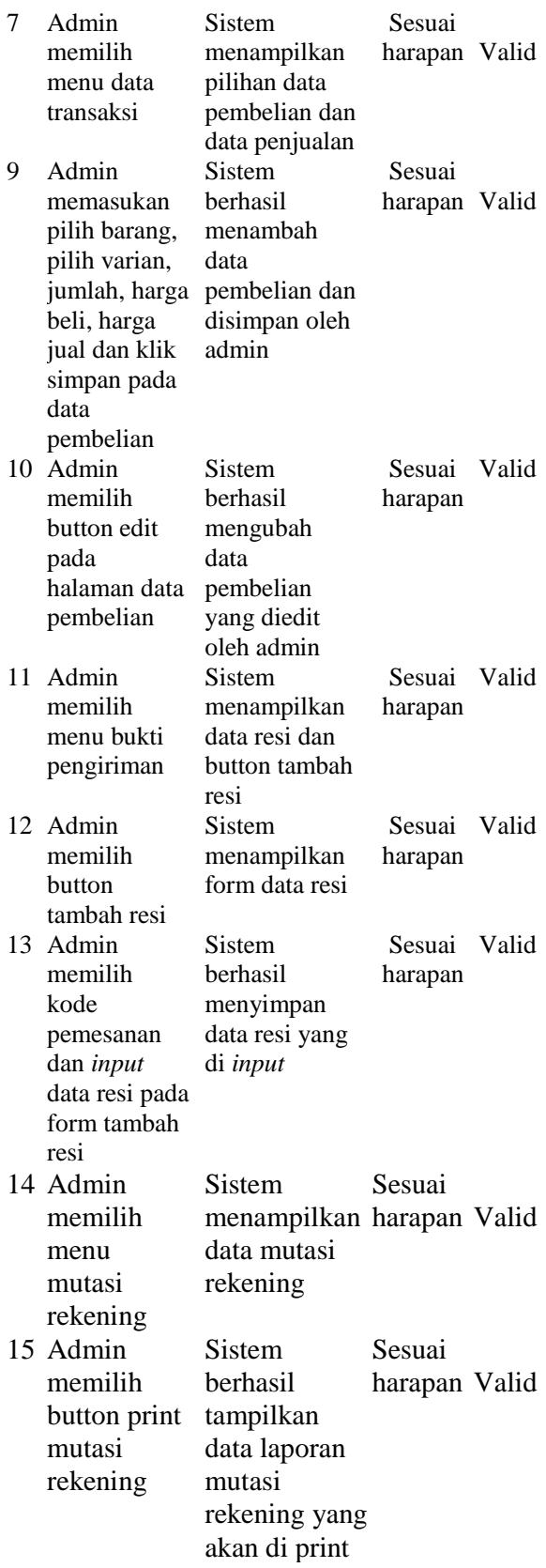

Sumber: Analisis Data Primer

\section{Implementasi Program}

Berikut adalah proses pembahasan interface atau antarmuka program: 


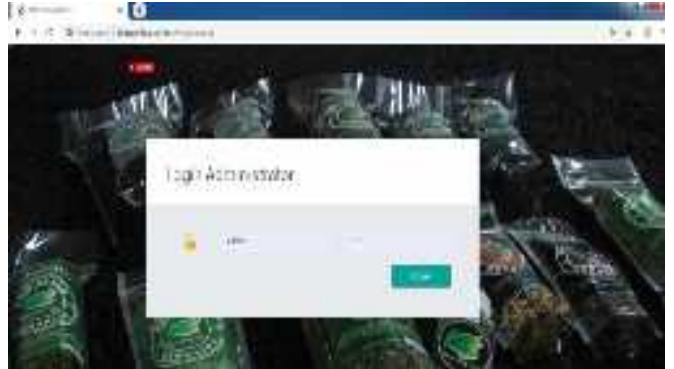

Gambar 7. Halaman login admin

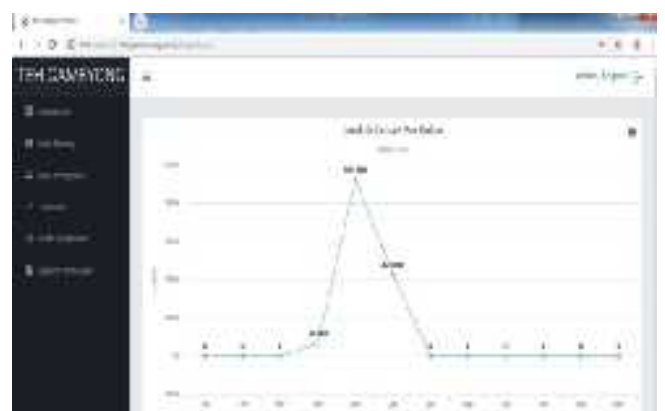

Gambar 8. Halaman beranda admin

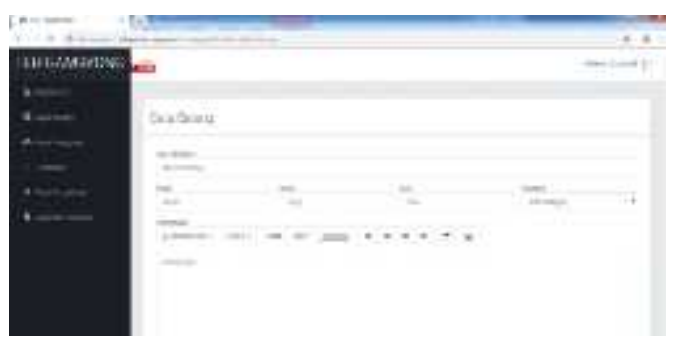

Gambar 9. Halaman master data barang

Pada halaman data barang terdapat fasilitas tambah untuk menambah data, edit untuk mengubah data, hapus untuk menghapus data.

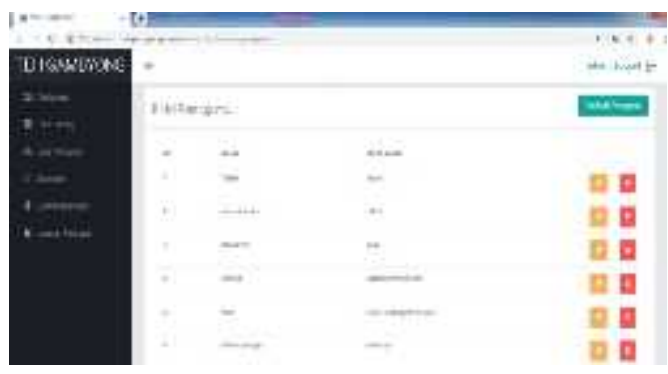

Gambar 10. Halaman tambah data pengguna

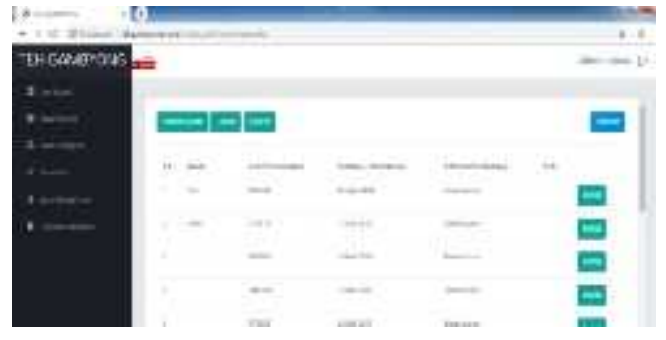

Gambar 11. Halaman data penjualan

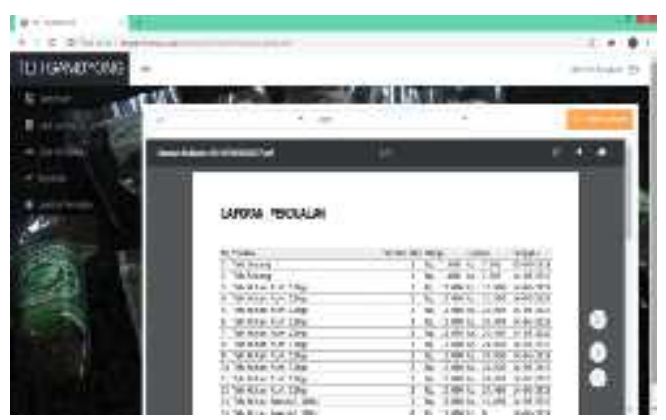

Gambar 12. Halaman laporan penjualan

Halaman laporan bukti pengiriman, menampilkan nama pelanggan, kode pemesanan, nomor resi, jasa kurir dan layanan kurir

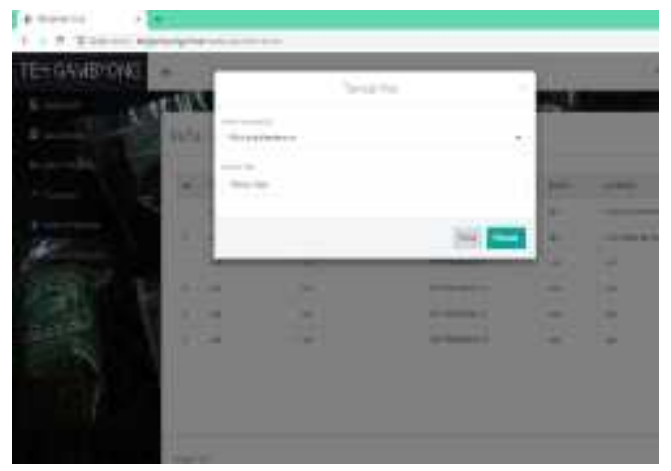

Gambar 13 Halaman bukti pengiriman 


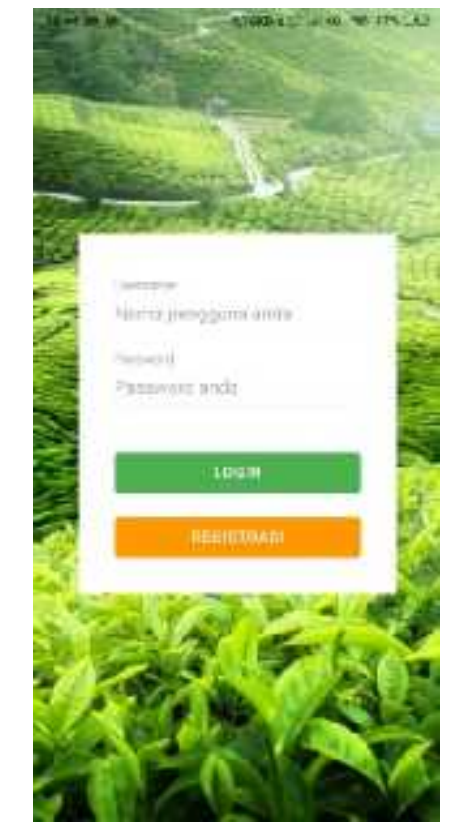

Gambar 14. Halaman login user

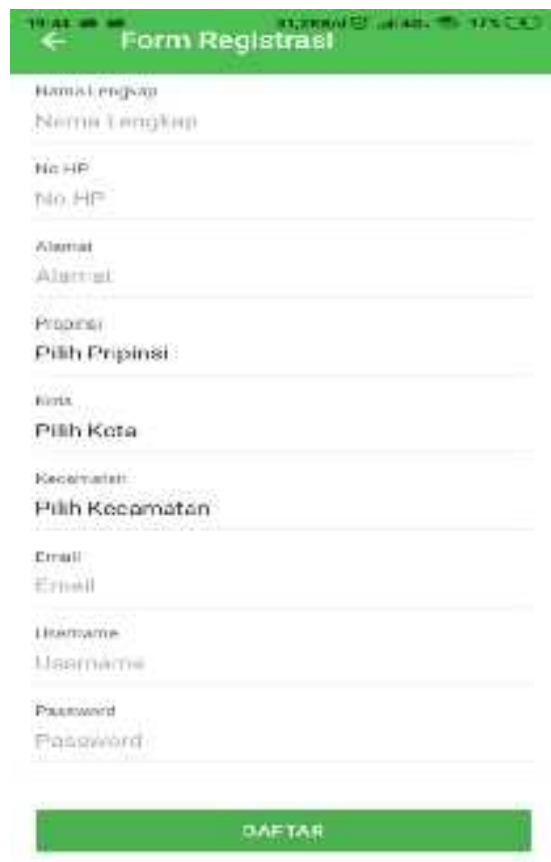

Gambar 15. Halaman form registrasi

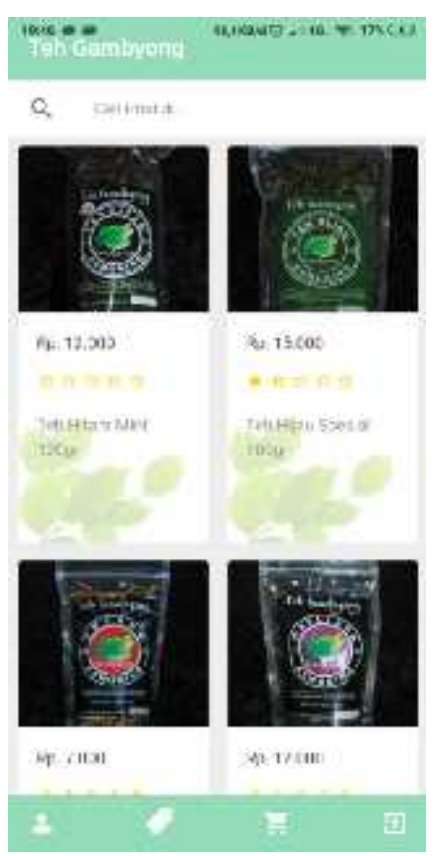

Gambar 16. Halaman utama user

Halaman detail produk berisi gambar produk yang dipilih, harga, rating, keterangan, dan stok produk.

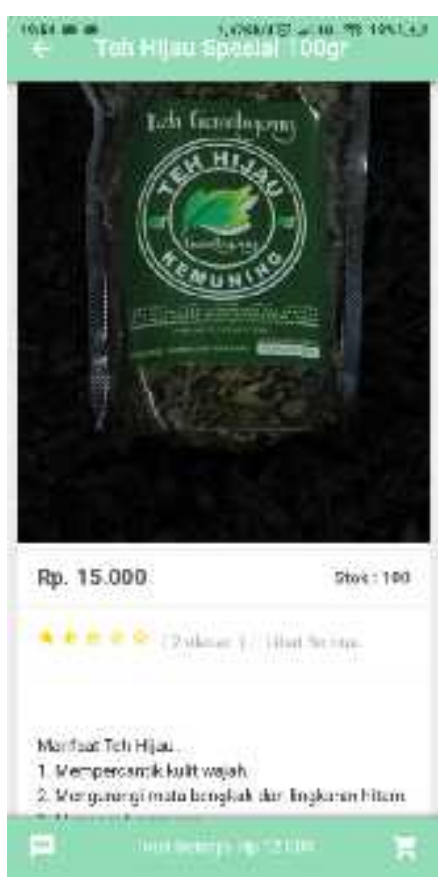

Gambar 17. Halaman detail Produk

Halaman keranjang belanja berisi daftar barang, nama penerima, telefon penerima, alamat penerima, kode pos, provinsi, kota, kecamatan, kelurahan, berat barang, kurir, layanan, dan ongkos kirim. 


\section{Analisa PIECES aplikasi}

Berikut adalah hasil analisa apakah suatu sistem baru itu layak atau tidak, menggunakan kriteria PIECES.

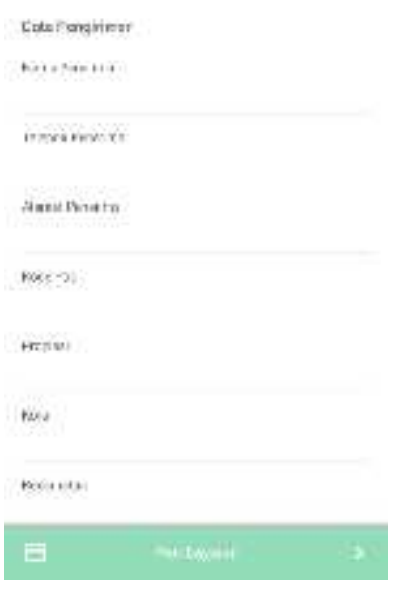

Tabel 2. Analisa PIECES

\begin{tabular}{|c|c|c|}
\hline Analisa & $\begin{array}{c}\text { Yang sedang } \\
\text { berjalan }\end{array}$ & $\begin{array}{l}\text { Yang akan } \\
\text { dibangun }\end{array}$ \\
\hline $\begin{array}{l}\text { Perfomance } \\
\text { (Kinerja) }\end{array}$ & $\begin{array}{l}\text { Pengolahan } \\
\text { data masih } \\
\text { dilakukan } \\
\text { secara } \\
\text { manual yaitu } \\
\text { pelanggan } \\
\text { memesan teh } \\
\text { by phone atau } \\
\text { langsung } \\
\text { datang ke teh } \\
\text { gambyong. }\end{array}$ & $\begin{array}{l}\text { Pengolahan } \\
\text { data dibantu } \\
\text { dengan } \\
\text { aplikasi } \\
\text { pemesanan teh } \\
\text { secara online, } \\
\text { sehingga } \\
\text { pelanggan } \\
\text { dapat } \\
\text { memesan } \\
\text { produk } \\
\text { aplikasi yang } \\
\text { ada. }\end{array}$ \\
\hline $\begin{array}{l}\text { Information } \\
\text { (Informasi) }\end{array}$ & $\begin{array}{l}\text { Informasi } \\
\text { mengenai } \\
\text { stok } \\
\text { persediaan } \\
\text { barang dan } \\
\text { update } \\
\text { barang } \\
\text { terbaru harus } \\
\text { menanyakan } \\
\text { langsung } \\
\text { kepada admin } \\
\text { teh } \\
\text { gambyong. }\end{array}$ & $\begin{array}{l}\text { Informasi } \\
\text { mengenai } \\
\text { produk dan } \\
\text { persediaan } \\
\text { selalu di } \\
\text { update dalam } \\
\text { aplikasi } \\
\text { tersebut. }\end{array}$ \\
\hline $\begin{array}{l}\text { Economy } \\
\text { (Ekonomi) }\end{array}$ & $\begin{array}{l}\text { Biaya yang } \\
\text { dikeluarkan } \\
\text { oleh } \\
\text { pelanggan } \\
\text { lumayan } \\
\text { tinggi karena } \\
\text { harus datang } \\
\text { ke toko teh } \\
\text { gambyong, } \\
\text { sedangkan } \\
\text { untuk } \\
\text { pelanggan } \\
\text { yang } \\
\text { memesan by } \\
\text { phone harus } \\
\text { memiliki } \\
\text { pulsa yang } \\
\text { mahal. }\end{array}$ & $\begin{array}{l}\text { Biaya yang } \\
\text { dibutuhkan } \\
\text { relatif rendah, } \\
\text { karena sistem } \\
\text { berbasis } \\
\text { android } \\
\text { sehingga } \\
\text { pelanggan } \\
\text { dapat } \\
\text { memesan } \\
\text { melalui } \\
\text { aplikasi. }\end{array}$ \\
\hline
\end{tabular}

Halaman metode pembayaran berisi informasi nominal yang harus dibayarkan, nomor rekening penjual, nama penjual.

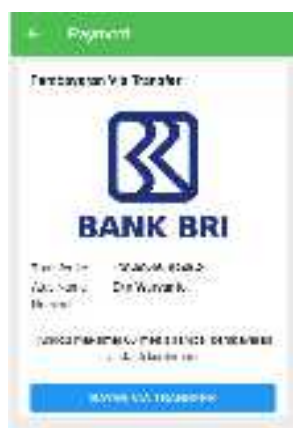

Gambar 4.16. Halaman pembayaran

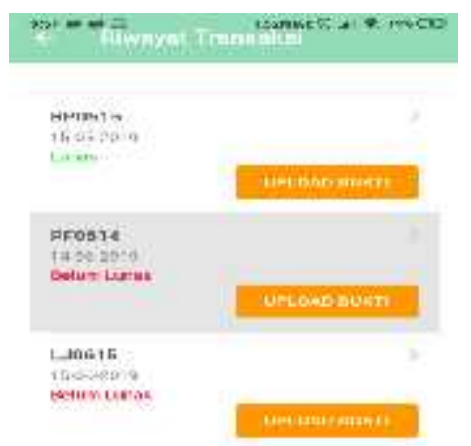

Gambar 4.17. Halaman metode pembayaran 


\begin{tabular}{|c|c|c|}
\hline $\begin{array}{l}\text { Control } \\
\text { (Keamanan) }\end{array}$ & $\begin{array}{l}\text { Keamanan } \\
\text { data sangat } \\
\text { kurang, } \\
\text { terlebih } \\
\text { apabila } \\
\text { terjadi } \\
\text { pesanan } \\
\text { produk yang } \\
\text { fiktif. }\end{array}$ & $\begin{array}{l}\text { Keamanan } \\
\text { data sudah } \\
\text { dibantu } \\
\text { dengan sistem, } \\
\text { setiap user } \\
\text { yang login } \\
\text { harus } \\
\text { melakukan } \\
\text { register } \\
\text { dengan data } \\
\text { yang valid. }\end{array}$ \\
\hline $\begin{array}{l}\text { Efficiency } \\
\text { (Efisiensi) }\end{array}$ & $\begin{array}{l}\text { Dalam } \\
\text { pengerjaan } \\
\text { pemasanan } \\
\text { produk serta } \\
\text { metode yang } \\
\text { pembayaran } \\
\text { masih } \\
\text { menggunakan } \\
\text { nota kertas } \\
\text { konvensional }\end{array}$ & $\begin{array}{l}\text { Dalam } \\
\text { pendataan } \\
\text { pesanan } \\
\text { pelanggan } \\
\text { sudah dibantu } \\
\text { dengan sistem } \\
\text { sehingga } \\
\text { memudahkan } \\
\text { dalam melihat } \\
\text { pesanan } \\
\text { pelanggan. }\end{array}$ \\
\hline $\begin{array}{l}\text { Service } \\
\text { (Layanan) }\end{array}$ & $\begin{array}{l}\text { Minimnya } \\
\text { pelayanan } \\
\text { kepada } \\
\text { pembeli } \\
\text { karena } \\
\text { kerbatasan } \\
\text { karyawan } \\
\text { yang ada di } \\
\text { teh } \\
\text { gambyong }\end{array}$ & $\begin{array}{l}\text { Layanan untuk } \\
\text { pelanggan } \\
\text { sudah baik } \\
\text { dengan adanya } \\
\text { aplikasi dan } \\
\text { bagi admin } \\
\text { juga } \\
\text { memberikan } \\
\text { kemudahan } \\
\text { dalam melihat } \\
\text { pesanan } \\
\text { pelanggan. }\end{array}$ \\
\hline
\end{tabular}

Sumber: Analisa Data Primer

\section{KESIMPULAN DAN SARAN}

Dari hasil perancangan penelitian ini dapat diambil kesimpulan bahwa, Teknologi pembangun aplikasi yang digunakan, masih efektif atau mampu untuk memenuhi kebutuhan tuntutan era digital seperti melakukan pengolahan data ,pengolahan transaksi, pengolahan laporan penjualan. Adanya aplikasi mobile dalam hal ini menggunakan android membuat media berbelanja Teh menjadi lebih mudah untuk masyarakat sehingga tujuan melestarikan produksi teh di Indonesia akan tercapai. Pelaku usaha teh menjadi lebih mudah dan mengelola data produk yang baru saja diproduksi atau sudah terjual sehingga dapat melakukan inovasi usahanya dan berkontribusi pada sektor pertanian khususnya teh di Indonesia.

Ada baiknya di masa mendatang dapat dikembangkan atau diteliti lebih lanjut dalam hal, aplikasi ini masih bisa dikembangkan untuk melakukan pembayarannya secara Otomatis dengan menggunakan Payment Gateway. Menambahkan fitur untuk pelacakan pengiriman barang sesuai nomor resi agar memudahkan pembeli dalam memantau sampai mana barang dikirim. Agar aplikasi sistem ini sempurna diperlukan pengembangan lebih lanjut terutama dalam menambahkan fitur produk terlaris dalam periode tertentu.

\section{DAFTAR PUSTAKA}

Ajisaka. 2012. Pengertian Teh. Jakarta : PT Raja.

Al Fatta. 2007. Analisis dan Perancangan Sistem Informasi. Yogyakarta : Andi

Asropudin Pipin, 2013. Kamus Teknologi Informasi. Bandung : Titian Ilmu

Iskandaria. 2012. Contoh Pengujian Black Box.

http://kafegue.com/contoh-pengujian-blackbox-testing/

Jogiyanto, H. M. 2005. Analisis dan Desain Sistem Informasi. Yogyakarta: Andi Offset.

Ladjamuddin. 2006. Rekayasa Perangkat Lunak cer-kell. Bandung

Prasetyo, Andri dan Susanti Rahel. 2016. Sistem Informasi Penjualan Berbasis Web Pada PT. Cahaya Sejahtera Sentosa Blitar

Pratiwi, Y. I., Ali, M., Setiawan, M. I., Budiyanto, H., \& Sucahyo, B. S. (2017). Urban Agriculture Technology to Support Urban Tourism. ADRI International Journal Of Agriculture, l(1).

Supardi, Ir. Yuniar. 2017. "Koleksi Program Tugas Akhir dan Skripsi dengan Android" . Jakarta : PT Elex Media Komputindo.

Sutabri, Tata 2012. Analisis Sistem Informasi. Yogyakarta: Andi. 